\title{
O PRÊMIO JOVEM CIENTISTA E O COMPORTAMENTO INFORMACIONAL DO PESQUISADOR
}

\author{
YOUNG SCIENTIST AWARD (PREMIO JOVEM CIENTISTA) AND THE INFORMATIONAL \\ BEHAVIOR OF THE RESEARCHER
}

Janaina Ferreira Fialho

Professora adjunta da Faculdade de Comunicação e Biblioteconomia da UFG (FACOMB)

Doutora em Ciência da Informação

janafialho@hotmail.com

\begin{abstract}
Resumo
$\mathrm{O}$ artigo apresenta os principais resultados alcançados num estudo que buscou investigar o comportamento informacional do jovem pesquisador brasileiro na prática da pesquisa científica. Utilizou-se uma amostra de 14 estudantes vencedores do Prêmio Jovem Cientista na categoria estudante de ensino médio, promovido pelo Conselho Nacional de Desenvolvimento Científico e Tecnológico. Através da aplicação da técnica de análise de conteúdo, o estudo orientou para a construção da rede semântica de representação do discurso científico, elaborada a partir do vocabulário utilizado pelos jovens pesquisadores nos textos de suas pesquisas. O Prêmio Jovem Cientista caracterizou-se como um momento importante na vida dos estudantes: em relação ao reconhecimento social, ao desenvolvimento da carreira profissional e ao aprendizado de pesquisa. Concluiu-se que um dos pontos frágeis do concurso é a divulgação junto à sociedade, principalmente o acesso limitado aos textos das pesquisas premiadas.
\end{abstract}

Palavras-chave: Comportamento informacional. Pesquisa científica - ensino médio. Prêmio Jovem Cientista. Análise de conteúdo.

\section{INTRODUÇÃO}

O Prêmio Jovem Cientista foi estabelecido pelo Conselho Nacional de Desenvolvimento Científico e Tecnológico (CNPq) em 1981 e caracteriza-se como um trabalho de parceria com empresas privadas, como o Grupo Gerdau e a Fundação Roberto Marinho. Os objetivos do prêmio são estimular a prática de pesquisa, descobrir estudantes talentosos e que demonstrem capacidade de solucionar problemas importantes para o país. Uma das finalidades da proposta é estimular os jovens a praticarem a pesquisa como meio de aquisição de aprendizado e conhecimento e, ao mesmo tempo, incentivá-los a seguir carreiras científicas e tecnológicas.

\footnotetext{
(c) (†) Esta obra está licenciada sob uma Licença Creative Commons.
} DOI 10.5007/1518-2924.2011v16n31p88 
Dessa forma, ele se divide em cinco categorias: 1) estudante de ensino médio; 2) estudante de graduação; 3) estudante graduado; 4) orientador e 5) mérito institucional.

Por meio de suas categorias de participação abertas ao público, propõe-se a cada ano um tema geral de pesquisa, dividido em tópicos, dentre os quais o estudante pode fazer a escolha. $\mathrm{O}$ tema proposto deve possuir relevância nacional e ser de interesse da população brasileira, como tem acontecido com as temáticas de alimentos (2004), educação (2001/2008), energia elétrica (2002), meio ambiente (2003/2006) e saúde (1999/2005). Na categoria ensino médio, estudantes regularmente matriculados em escolas públicas e privadas e em escolas técnicas, com menos de 25 anos de idade, constituem o público credenciado para a participação no concurso.

A cada edição do prêmio, os ganhadores, nas posições de $1^{\circ}, 2^{\circ}$ e $3^{\circ}$ lugares, são contemplados com prêmios como computadores e bolsas de iniciação científica júnior, e têm a oportunidade de participar das reuniões anuais da Sociedade Brasileira para o Progresso da Ciência (SBPC), com o objetivo de demonstrar os resultados de suas pesquisas. É crescente a participação de estudantes de todo o país, como pôde ser percebido no ano de 2008, com ocorrência de 970 inscrições somente para a categoria ensino médio.

A escola tem um papel fundamental em todo o processo, responsável principalmente pelos aspectos da divulgação, incentivo e esclarecimento de dúvidas. Por meio do acompanhamento do professor orientador, estabelece-se uma data limite para a entrega da pesquisa, estimula-se o trabalho integrado entre as disciplinas e orienta-se os estudantes sobre os diversos aspectos da pesquisa, como apresentação, organização, clareza, capacidade de argumentação, coerência entre as ideias, criatividade, exemplos concretos da vida cotidiana, relevância da abordagem, rigor na metodologia e citação das fontes de informação utilizadas nos trabalhos. Os estudantes devem buscar informações primeiramente em suas escolas, principalmente com os professores. Outra forma de buscar informações adicionais é através do site oficial do Prêmio Jovem Cientista na internet ${ }^{1}$.

A proposta constitui-se da elaboração de redação de três páginas, em que se exige certa profundidade na abordagem, na reunião dos dados e explicação dos argumentos. O texto deve

1 Informações sobre o regulamento, inscrições, curiosidades sobre o tema, notícias, esclarecimento de dúvidas, atualidades e até um boletim informativo sobre o prêmio estão disponíveis. Disponível em: $<$ http://www.jovemcientista.org.br/> . Acesso em: 2 abr. 2009. 
se orientar pela ordenação lógica das ideias em introdução, desenvolvimento e conclusão. $\mathrm{Na}$ introdução, os organizadores sugerem que o autor apresente as ideias, hipóteses e justificativa do tópico escolhido; no desenvolvimento, a explicação da elaboração da pesquisa e os resultados obtidos, e as conclusões devem se remeter às argumentações sobre a ideia inicial, fundamentadas nos resultados obtidos.

As pesquisas são julgadas através de critérios como qualidade do texto, observando a linguagem (clareza e objetividade); originalidade; contribuição de conhecimento (melhoria da qualidade de vida da população e solução de problemas cotidianos) e qualidade de apresentação dos trabalhos. O desenvolvimento da redação sugere que, primeiramente, a escola cumpra sua função de divulgar bem o concurso junto à comunidade escolar; os professores discutam o tema com os estudantes em sala de aula, seu significado e possíveis abordagens; o estudante defina o seu tópico de pesquisa e tenha uma interação contínua com o orientador, em todas as fases da pesquisa.

Através do acesso integral aos trabalhos produzidos pelos estudantes, objetivou-se demonstrar neste artigo a identificação, sistematização e representação do discurso científico dos vencedores do Prêmio Jovem Cientista. Para atingir tal objetivo, as pesquisas premiadas foram submetidas aos métodos de análise de conteúdo e comparação com a estrutura do artigo científico. O trabalho se insere no âmbito do uso da informação e pretende demonstrar a técnica da análise de conteúdo como possibilidade potencial para complementar outras metodologias em estudos de letramento informacional.

Os resultados apresentados, oriundos da pesquisa de doutorado, não contemplam o conjunto completo de técnicas aplicadas para investigar o comportamento informacional dos estudantes premiados, como as entrevistas e a observação participante na comunidade do prêmio na rede social Orkut. Por questões metodológicas, ou seja, a forma como os estudantes foram abordados originalmente na pesquisa, as entrevistas e a observação participante foram exploradas separadamente em artigo recente da literatura nacional, as quais demonstram detalhadamente as ações, os pensamentos, os sentimentos e as estratégias dos estudantes no processo da pesquisa científica. 


\section{REFERENCIAL TEÓRICO}

No centro da questão de formação de pesquisadores na educação básica (ensino fundamental e médio), a Ciência da Informação e a Biblioteconomia têm desenvolvido um conjunto de reflexões teóricas e práticas profissionais que buscam alcançar alguns avanços e que possam contribuir positivamente para o processo de ensino-aprendizagem dos estudantes. Verifica-se, nessas áreas, o desenvolvimento de campos de estudo e conceitos de abrangência ampla, que oferecem suporte à discussão do assunto, como o comportamento informacional de jovens e o conceito de letramento informacional. O comportamento informacional de adolescentes e jovens está inserido num campo mais amplo de pesquisa, que é o comportamento informacional humano; o qual perpassa por diferentes instâncias, como a orientação e aprendizado do letramento informacional e o design da tecnologia (CHELTON; COOL, 2004).

Considerando-se a contribuição da ciência cognitiva para o entendimento do comportamento informacional de jovens, o conceito de letramento informacional tem se revelado como um fundamento teórico importante para se compreender como eles buscam e usam informação em suas atividades de pesquisa. O conceito tem configurado uma parte substancial das pesquisas na literatura internacional. É um conceito abrangente, que inclui uma série de habilidades de identificação, seleção, busca e uso de informações necessárias ao bom desempenho dos estudantes no relacionamento com o universo informacional. Em 1998, a Associação Americana de Bibliotecários Escolares e a Associação para Tecnologia e Comunicações Educacionais apresentaram um relatório atualizado, denominado Padrões de Letramento Informacional para o Aprendizado Estudantil.

O documento indica uma estrutura conceitual e diretrizes gerais que descrevem o perfil do estudante inserido no universo do letramento informacional, o qual se orienta por três eixos: o aprendizado do estudante; o aprendizado independente e a responsabilidade social. As primeiras competências ressaltadas dizem respeito a uma conduta mais consciente em relação à localização e ao acesso à informação durante a busca, como a formulação de boas questões de pesquisa, o reconhecimento da necessidade de informação precisa e completa, o conhecimento da organização e a disponibilização das fontes de informação, a formulação de estratégias de busca adequadas e a identificação de fontes confiáveis. 
A partir das informações encontradas, a expectativa é de que os estudantes trabalhem de forma reflexiva sobre as mesmas, relacionando-as à questão a ser resolvida, integrando-as aos conhecimentos prévios, discernindo a diversidade de ideias e abordagens, bem como a diferença entre textos opinativos e informativos. Envolve-se aí também a habilidade de trabalhar coletivamente e de suscitar debates e trocas de ideias e a comunicação das mesmas em formatos apropriados. Todo esse procedimento pode conduzir o estudante a um uso ético da informação, incluindo o respeito à propriedade intelectual. O pressuposto é que, à medida que adquirem essas habilidades, os estudantes demonstrem certa autonomia em relação à construção do próprio aprendizado.

O aprendizado de pesquisa na educação básica parece ser um problema crítico no Brasil, conforme apontam diversas pesquisas das áreas de Educação e Biblioteconomia (ABREU, 2002; CAMPELLO, 2000; MAGALHÃES, 1992; NEVES, 2000). Nesses estudos, os principais problemas apontados são o plágio das informações, a ausência do acompanhamento adequado por parte do professor, a falta de clareza quanto aos objetivos da pesquisa e a prática da cópia, potencializada pelo uso da Internet. Como preparar os estudantes para a iniciação científica nas escolas? Do ponto de vista do letramento informacional, as pesquisas em andamento sugerem que o trabalho deve ser gradativo e pode ocorrer desde o ensino fundamental e que bibliotecários escolares e professores podem trabalhar juntos para desenvolver as habilidades informacionais nos estudantes (CAMPELLO, 2003; KUHLTHAU, 2004).

A práxis científica compreende "o conjunto das atividades desempenhadas pelos cientistas, tendo por finalidade a produção de novos conhecimentos científicos" (MESQUITA FILHO, 2000). A comunicação científica caracteriza-se como a atividade primordial à sustentabilidade da prática de pesquisa científica, a qual inclui as atividades de produção, disseminação e uso da informação, do momento da concepção da ideia da pesquisa até a aceitação dos resultados como parte integrante do conhecimento científico (GARVEY, 1979). A linguagem é parte fundamental do processo da discursividade científica, podendo-se reconhecer na linguagem científica a disposição dos elementos da argumentação e a suposta neutralidade do fazer científico.

Dentre as diversas definições do discurso, adota-se, para este trabalho, a concepção do discurso como prática social, como um evento que vai além das palavras e do texto 
propriamente dito. Nessa abordagem, Focault (1987) afirma que "os discursos são feitos de signos. Mas o que fazem é mais que utilizar esses signos para designar coisas. É esse mais que os torna irredutíveis à língua e ao ato de fala. É esse mais que é preciso fazer aparecer e que é preciso descrever" (p. 56). Na mesma perspectiva, Van Dijk (1999) define o discurso como um evento comunicativo complexo, determinado por características do contexto social. Dessa forma, o discurso científico é tratado por Chauí (1990) como o "discurso competente", ouvido e aceito socialmente.

Kobashi (1994) revela que uma característica central do discurso é operar em duas instâncias: a enunciação, a abordagem interna do texto, e a análise externa do contexto sócio-histórico em que ele se insere. Nessa abordagem, advoga-se a ideia de que o discurso deve ser abordado em sua dimensão social, em três concepções: a) a relação do discurso com a enunciação e as condições de produção e recepção; b) o discurso como lugar do social e do individual; c) a articulação entre narrativa e discurso, ou o discurso constituído sobre estruturas narrativas que lhe dão sustentação (KOBASHI, 1994).

A análise de conteúdo é a técnica que tem o texto como principal unidade de análise. Segundo Kientz (1973), os procedimentos de construção da análise do conteúdo variam segundo os objetivos da pesquisa e o tipo de material a ser trabalhado. Berelson (1952) estabelece quatro exigências fundamentais para a utilização do método: 1) ser objetivo; 2) ser sistemático; 3) abordar apenas o conteúdo temático e 4) exercer a quantificação. Deve-se definir com clareza e precisão as unidades, categorias e escalas, de modo que outro pesquisador, ao utilizar os mesmos recursos, chegue aos mesmos resultados. Do mesmo modo, deve-se sistematizar todo o conteúdo decorrente do problema estudado e não apenas os elementos que corroboram com as teses do pesquisador.

A história da análise de conteúdo está vinculada a uma resposta à explosão das mensagens veiculadas nos veículos de comunicação de massa na década de 1930 nos Estados Unidos, a qual permitiria uma análise mais objetiva e rigorosa. Bernard Berelson, um de seus principais promotores, a definiu como "uma técnica de pesquisa para a descrição objetiva, sistemática e quantitativa do conteúdo manifesto das comunicações, tendo por finalidade interpretá-las" (BERELSON, 1952, p. 18). Berelson (1952) adverte que, se há um desejo de sucesso na aplicação do método, torna-se necessário ter uma noção precisa de seus limites e possibilidades. 
A análise de conteúdo é um instrumento científico de pesquisa de múltiplas aplicações, tendo sido bastante explorada no campo da crítica literária, da Comunicação, da Psicologia, da Sociologia e nas Ciências Políticas. A obra clássica sobre seu procedimento pode ser encontrada em Bardin (2002), professora de Psicologia da Universidade Paris V, que aplicou as técnicas de análise de conteúdo à investigação psicossociológica e aos estudos de comunicação de massa. Sua obra é um referencial claro, concreto e operacional do método, que desenvolve um panorama teórico e prático de utilização. Segundo Bardin (2002, p. 38), a análise de conteúdo é "um conjunto de técnicas de análise das comunicações que utiliza procedimentos sistemáticos e objetivos de descrição do conteúdo das mensagens". Para Rocha e Deusdará (2005), a análise de conteúdo objetiva principalmente o enriquecimento da leitura, aumentando a produtividade e pertinência da análise.

Minayo (1996) explica que a trajetória da análise de conteúdo faz parte de um esforço histórico secular. No decorrer dos anos e de seu desenvolvimento, seu principal viés de legitimação é uma suposta significação profunda e encoberta do texto que precisa ser recuperada (ROCHA; DEUSDARÁ, 2005). Segundo Minayo (1996), é possível identificar cinco técnicas de análise de conteúdo: análise da expressão, análise das relações, análise de avaliação ou representacional; análise da enunciação e análise temática.

A noção de tema "está ligada a uma afirmação a respeito de determinado assunto... pode ser representada por uma palavra, uma frase, um resumo" (MINAYO, 1996, p. 208). O trabalho de análise temática consiste em descobrir os núcleos de sentido presentes no texto, cuja presença ou frequência tenham significado para o objeto estudado (MINAYO, 1996). Operacionalmente, Bardin (2002) estrutura a análise temática em três etapas: a) pré-análise que se subdivide nas tarefas de leitura flutuante, constituição do corpus, formulação de hipóteses e objetivos, preparação do material e referenciação dos índices/elaboração dos indicadores; b) exploração do material e c) tratamento dos resultados, inferência e interpretação.

A exigência da quantificação, inicialmente restrita metodologicamente pela contagem de palavras, símbolos e temas, beneficiou-se de numerosas contribuições no campo metodológico (KIENTZ, 1973). Pode-se incluir nessa perspectiva o estudo do contexto, que pode modificar o sentido dos elementos da mensagem. Kientz (1973) destaca o trabalho de Charles Osgood, que colocou no centro das pesquisas o estudo do contexto, por meio da 
análise de contingência. Essa, por sua vez, não ignora as frequências, mas busca as associações por proximidade espacial ou implicações lógicas, ou seja, que se possibilite a visualização da relação entre os elementos do corpus.

\section{METODOLOGIA}

\subsection{Universo de pesquisa e caracterização da amostra}

O Prêmio Jovem Cientista contabilizava, à época da pesquisa, 24 estudantes vencedores em todas as suas edições. Cabe explicar que, embora tenha sido criado em 1981, a categoria dos estudantes de ensino médio só foi incluída em 1999. No primeiro momento, optou-se por demonstrar o universo completo dos estudantes vencedores para se ter uma visualização do prêmio no cenário nacional. Os 24 vencedores se encontravam dispersos pelo país nas regiões Sudeste (50\%), Nordeste (29,13\%), Norte (4,16\%), Centro-Oeste $(8,33 \%)$ e Sul $(8,32 \%)$.

A população vencedora do prêmio se mostrou bastante homogênea em relação à distribuição por gênero, constituindo-se de $54 \%$ de mulheres e $46 \%$ de homens. E ainda, $46 \%$ dos estudantes eram provenientes de escolas públicas (estaduais e federais), 34\% de particulares e $20 \%$ de escolas filantrópicas, mantidas pela Fundação Bradesco. Por escola filantrópica entende-se que é a "instituição de educação que presta serviços à população em geral, em caráter complementar às atividades do Estado, sem qualquer remuneração"².

Embora o universo de jovens vencedores compreendesse 24 pesquisadores, a amostra de pesquisa se constituiu de 14 pesquisadores, provenientes dos estados da Bahia, Ceará, Goiás, Minas Gerais, Paraná, Piauí, Rio de Janeiro, Rio Grande do Norte, Santa Catarina e São Paulo. Um dos maiores desafios da pesquisa foi o contato com os estudantes; a amostra não foi selecionada de forma intencional, mas pela possibilidade de acesso aos mesmos. Logo, os estudantes excluídos o foram por impossibilidade de contato, após inúmeras tentativas por telefone, e-mail e buscas nas redes sociais.

Com o objetivo de compreender a dinâmica dos estudantes bem-sucedidos, foi possível trabalhar com os ganhadores do Prêmio Jovem Cientista dos anos de 2001, 2002, 2003, 2004,

2 Tesauro Brasileiro da Educação. INEP. Disponível em: < http://www.inep.gov.br/pesquisa/thesaurus/thesaurus.asp?te1 $=31674 \&$ te $2=32679 \&$ te $3=120850 \&$ te 4=39036\&te5=148115\&te6=32699 > . Acesso em: 2 abr. 2009. 
2005, 2006 e 2008. Houve proporcionalidade entre os gêneros, já que a amostra compreendeu sete homens e sete mulheres, correspondente a quase $60 \%$ do universo da pesquisa, conforme demonstrado no QUADRO 1:

\begin{tabular}{|c|c|c|c|}
\hline Título da pesquisa & Autor & Escola & Cidade \\
\hline $\begin{array}{l}\text { Grupo de estudos: a troca de experiências e idéias } \\
\text { facilita a aprendizagem (2001) }\end{array}$ & $\begin{array}{c}\text { Conceição de } \\
\text { Maria F. da } \\
\text { Silva } \\
\end{array}$ & $\begin{array}{l}\text { Colégio Fundação } \\
\text { Bradesco }\end{array}$ & $\begin{array}{l}\text { Aparecida de } \\
\text { Goiânia/GO }\end{array}$ \\
\hline A eletricidade (2001) & $\begin{array}{l}\text { Leonardo de } \\
\text { Souza Araújo }\end{array}$ & $\begin{array}{l}\text { Centro Educacional } \\
\text { Manuel Pereira }\end{array}$ & Queimados/RJ \\
\hline $\begin{array}{l}\text { Construção e análise do rendimento de um coletor } \\
\text { solar (2002) }\end{array}$ & $\begin{array}{l}\text { Phillipe } \\
\text { Schaeffer } \\
\text { Werneck }\end{array}$ & $\begin{array}{l}\text { Colégio de Aplicação } \\
\text { João XXIII - UFJF }\end{array}$ & Juiz de Fora/MG \\
\hline Racionamento X uso racional (2002) & $\begin{array}{l}\text { Flávia Pedrosa } \\
\text { Costa }\end{array}$ & $\begin{array}{l}\text { Colégio Imaculada } \\
\text { Conceição }\end{array}$ & $\begin{array}{c}\text { Belo } \\
\text { Horizonte/MG }\end{array}$ \\
\hline $\begin{array}{l}\text { Consumo de energia elétrica na Vila Cordazzo } \\
\qquad(2002)\end{array}$ & $\begin{array}{c}\text { Joseli } \\
\text { Franceschet }\end{array}$ & Colégio SuperAtivo & Joaçaba/SC \\
\hline Dicionário aquoso (2003) & Renata Bossle & Colégio Ideal & $\begin{array}{l}\text { São José dos } \\
\text { Pinhais/PR }\end{array}$ \\
\hline $\begin{array}{l}\text { Alimentação e informação: solução para a fome } \\
(2004)\end{array}$ & $\begin{array}{l}\text { Magno Ivo } \\
\text { Silva Santos }\end{array}$ & $\begin{array}{l}\text { Escola Estadual Doutor } \\
\text { Carlos Albuquerque }\end{array}$ & $\begin{array}{c}\text { Montes } \\
\text { Claros/MG }\end{array}$ \\
\hline $\begin{array}{l}\text { Segurança alimentar e o combate ao desperdício: } \\
\text { pensar global para agir local (2004) }\end{array}$ & $\begin{array}{l}\text { Ronaldo } \\
\text { Márcio Soares } \\
\text { Brito }\end{array}$ & $\begin{array}{l}\text { Escola de Educação } \\
\text { Básica e Profissional } \\
\text { Fundação Bradesco }\end{array}$ & Caucaia/CE \\
\hline $\begin{array}{l}\text { Efeitos da radiação ionizante sobre a medula óssea } \\
\text { de camundongos C57BL/6 (2005) }\end{array}$ & $\begin{array}{c}\text { Mariana } \\
\text { Rietmann da } \\
\text { Cunha Madeira }\end{array}$ & $\begin{array}{l}\text { Colégio São Vicente de } \\
\text { Paulo }\end{array}$ & $\begin{array}{l}\text { Rio de } \\
\text { Janeiro/RJ }\end{array}$ \\
\hline $\begin{array}{l}\text { Estética nos salões de beleza de Salvador: } \\
\text { satisfação pessoal ou risco à saúde (2005) }\end{array}$ & $\begin{array}{c}\text { Esdras dos } \\
\text { Santos } \\
\text { Nascimento }\end{array}$ & $\begin{array}{l}\text { Colégio Estadual Luiz } \\
\text { Pinto de Carvalho }\end{array}$ & Salvador/BA \\
\hline $\begin{array}{l}\text { Controle de emissão de poluentes: conseqüências e } \\
\text { soluções da evolução dos objetivos científicos } \\
\text { (2006) }\end{array}$ & Felipe Arditti & $\begin{array}{l}\text { Escola Brasileira Israelita } \\
\text { Chaim Nachman Bialik }\end{array}$ & São Paulo/SP \\
\hline $\begin{array}{c}\text { Fogão solar: uma alternativa para sustentabilidade } \\
\text { da biodiversidade (2006) }\end{array}$ & $\begin{array}{l}\text { Jarbas Batista } \\
\text { Silva Araújo }\end{array}$ & $\begin{array}{l}\text { Escola Estadual Dom } \\
\text { Nivaldo Monte }\end{array}$ & Parnamirim/RN \\
\hline $\begin{array}{l}\text { Efeito do extrato aquoso de folhas da espécie } \\
\text { exótica Leucaena leucocephala na germinação e } \\
\text { no desenvolvimento de suas plântulas: uma } \\
\text { alternativa para o seu manejo no Parque Ecológico } \\
\text { da Pampulha - BH (2006) }\end{array}$ & $\begin{array}{c}\text { Andreia } \\
\text { Evangelista dos } \\
\text { Santos }\end{array}$ & CEFET/MG & $\begin{array}{c}\text { Belo } \\
\text { Horizonte/MG }\end{array}$ \\
\hline $\begin{array}{l}\text { Fatores que contribuem para violência na escola } \\
\qquad(2008)\end{array}$ & $\begin{array}{c}\text { Priscila } \\
\text { Oliveira Costa }\end{array}$ & $\begin{array}{l}\text { Escola de Educação } \\
\text { Básica e Profissional } \\
\text { Emb. Espedito de F. } \\
\text { Resende (Fundação } \\
\text { Bradesco) }\end{array}$ & Teresina/PI \\
\hline
\end{tabular}

Quadro 1: Caracterização da amostra

Fonte: Dados da pesquisa (2009).

Nos períodos apresentados, os temas sugeridos pela organização do prêmio foram: novas metodologias para a educação (2001); energia elétrica: geração, transmissão, distribuição e uso racional (2002); água - fonte da vida (2003); produção de alimentos: busca de soluções para a fome (2004); sangue: fluido da vida (2005); gestão sustentável da biodiversidade: desafio do milênio (2006); educação para reduzir as desigualdades sociais (2008). A maioria 
das pesquisas foi concebida como uma demanda do concurso, embora algumas tenham evoluído de projetos anteriores desenvolvidos nas escolas. Nesse sentido, uma estudante era bolsista de pesquisa do Departamento de Patologia da Fundação Osvaldo Cruz (Fiocruz) e sua pesquisa foi uma extensão do trabalho que já era desenvolvido no laboratório. É importante salientar também que todas as pesquisas foram publicadas nos cadernos do prêmio, produzidos pela Fundação Roberto Marinho, no Rio de Janeiro.

\section{APRESENTAÇÃO E ANÁLISE DOS DADOS}

\subsection{A representação da discursividade científica}

Neste trabalho, a identificação, sistematização e representação do perfil discursivo científico no corpus foi possível pelas seguintes fases: 1) definição do objetivo da análise de conteúdo; 2) definição do corpus a ser trabalhado; 3) decomposição do mesmo em unidades ou termos representativos da linguagem científica; 4) sistematização e identificação da frequência da terminologia; 5) análise do contexto e 6) estabelecimento das zonas de orientação.

O objetivo da análise de conteúdo foi a identificação, sistematização e representação do perfil discursivo dos jovens pesquisadores, iniciadas com a etapa da leitura flutuante ou de primeiro contato com as pesquisas produzidas, conforme sugerido por Bardin (2002). Nessa fase, foi possível identificar uma dinâmica comum no discurso dos trabalhos, evidenciada pelo vocabulário utilizado nas pesquisas. Através da leitura flutuante, observou-se um conjunto de palavras que se repetiam nos textos das pesquisas, o qual se constituiu como a principal categoria da análise de conteúdo.

O quadro semântico da pesquisa foi construído a partir da extração dos registros presentes no corpus, retirados do título, do texto e dos anexos das pesquisas, conforme a fase de exploração do material sugerida por Bardin (2002). Tais registros foram selecionados a partir da linguagem natural, ou seja, aqueles constantes nos textos das pesquisas. Esses, selecionados de forma intencional, não incluíram aqueles mais peculiares de cada área de conhecimento, mas apenas palavras comuns presentes nos textos. Por sua vez, o corpus analisado constituiu-se das 14 pesquisas premiadas por ocasião do concurso Prêmio Jovem Cientista. O quadro semântico demonstrou o vocabulário encontrado nos trabalhos dos 14 pesquisadores (P1 a P14), bem como a ocorrência do registro em cada um deles; onde 0 
significou a ausência do registro no texto da pesquisa, e 1, a presença do mesmo, conforme a configuração do software NetDraw 2.086 (BORGATTI, 2002).

Após a identificação, sistematização e frequência das unidades de registro do corpus, procedeu-se à análise contextual dos mesmos, cujo principal objetivo foi identificar as relações de sentido entre os registros na estrutura dos textos. Desse trabalho, originou-se o quadro da análise contextual, que apresentou os registros contextualizados nas pesquisas produzidas. No corpus foi possível verificar relações de equivalência, como a sinonímia ${ }^{3}$, por meio dos conceitos estudo/trabalho/pesquisa e pesquisa/monografia, os quais foram preservados em seus contextos originais. Observou-se também que o uso do mesmo conceito por vários pesquisadores manteve um sentido permanente, ou seja, o conceito usado por um pesquisador foi usado por todos os outros com o mesmo significado.

Em relação à frequência dos registros, buscou-se identificar aqueles de maior ocorrência na amostra. Com esse objetivo, elaborou-se um quadro que pudesse demonstrar os conceitos mais recorrentes, separando-os por número de aparições nas pesquisas. Houve também o interesse em localizá-los na pesquisa, ou seja, em que parte exatamente do texto eles estavam evidentes. A partir dessa análise, foram identificadas seis zonas de orientação no corpus: a) Análise - análise e interpretação dos dados; b) Geral - ausência de uma zona específica, realçando aspectos gerais da pesquisa; c) Metodologia - métodos do trabalho; d) Planejamento da pesquisa - organização e estruturação prévias da pesquisa; e) Recomendações recomendações e sugestões para trabalhos futuros e f) Referencial teórico - corpo teórico utilizado na pesquisa. Por serem extensos, o quadro semântico da pesquisa, o quadro de análise contextual e o de freqüência e zonas de orientação não foram incluídos no corpo do artigo, mas se encontram disponíveis integralmente no trabalho original.

Diante dos diferentes campos do saber e suas especificidades na produção de conhecimento, foi possível identificar no corpus um perfil discursivo comum, que caracterizou o perfil de trabalhos acadêmicos/científicos, por meio da análise possibilitada pelo software NetDraw 2.086 (BORGATTI, 2002). Inicialmente, o perfil foi identificado pela linguagem utilizada pelos pesquisadores em suas pesquisas e pelo plano de exposição das mesmas. A fase do tratamento e exploração dos resultados, sugerida por Bardin (2002), é ressaltada por meio do

3 No campo de estudos da linguagem, diz-se sinonímia quando se usa grafias diferentes para representar o mesmo significado. 
uso do software e do estabelecimento do relacionamento conceitual entre as pesquisas premiadas, na qual foi possível o estabelecimento da rede semântica, visualizada na FIG. 1.

Dentre as noções adotadas na literatura, o conceito de redes remete à ideia de um conjunto de nós e elos, uma estrutura sem fronteiras e sem limites geográficos. Conforme apontado por Marteleto (2001, p. 72), a análise de redes não constitui um fim em si mesma, mas "é o meio para se realizar uma análise estrutural cujo objetivo é mostrar em que a forma da rede é explicativa dos fenômenos analisados". A rede abaixo demonstra o fluxo semântico das pesquisas, cujos pesquisadores são representados pelos nós amarelos, os conceitos com menos de três ocorrências, pelos círculos cinza e os com três ou mais ocorrências, pelos vermelhos, totalizando 100 nós e 206 relacionamentos:

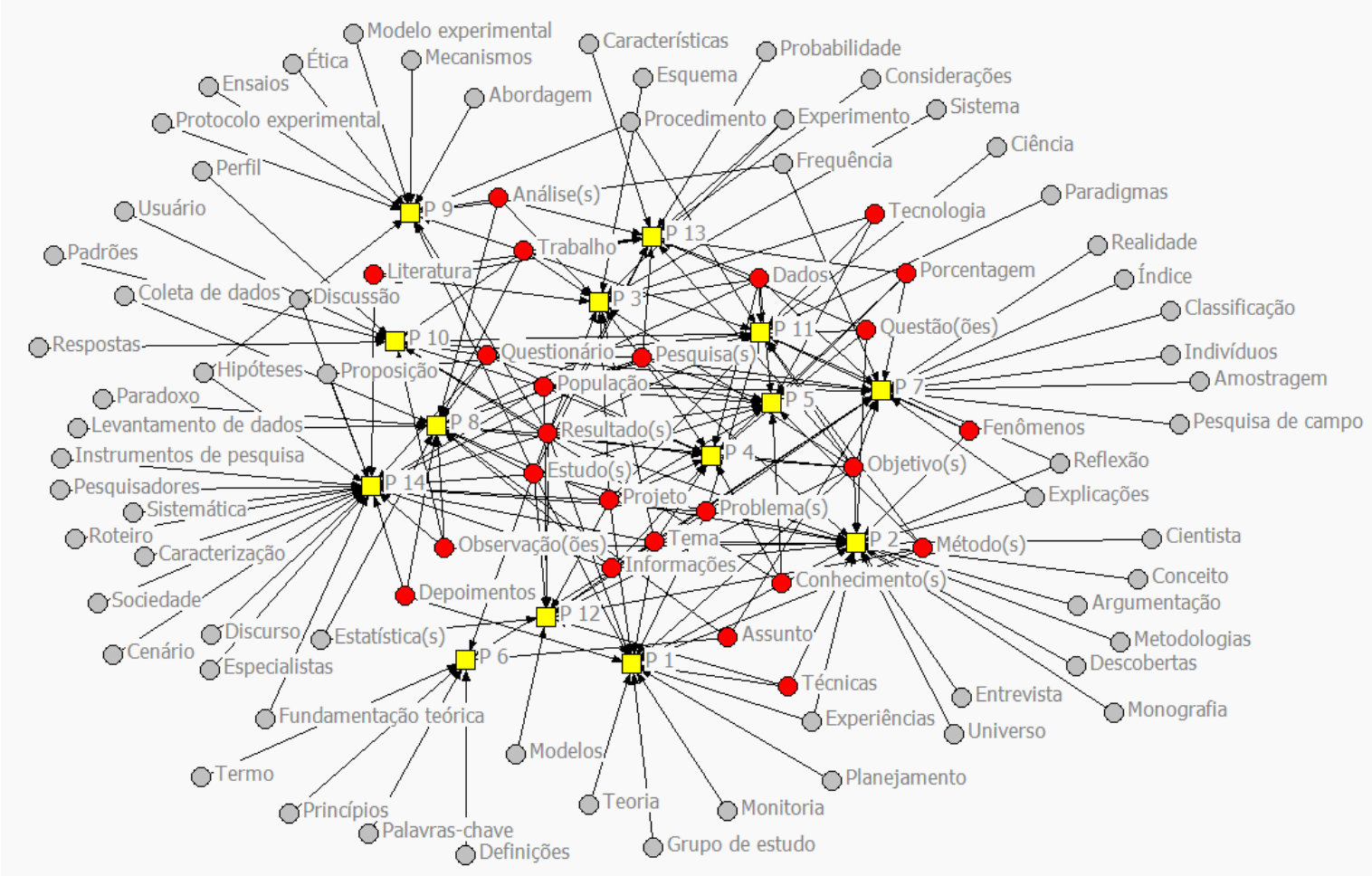

Figura 1: Rede semântica

Fonte: Dados da pesquisa (2009).

Constata-se a visualização dos conceitos e seus relacionamentos no contexto de produção das pesquisas, como os mais incidentes e compartilhados nos trabalhos dos jovens pesquisadores, tais como: análise (P3, P8, P9 e P13); assunto (P6, P7 e P8), conhecimento (P1, P2, P4, P5 e P10), dados (P3, P4, P5, P7, P8, P11 e P13), depoimentos (P1, P8 e P14), estudos (P1, P2, P5, P8, P9, P12, P13 e P14), fenômenos (P2, P7 e P11), informações (P2, P4, P7, P8 e P14), 
literatura (P3, P13 e P14), método (P1, P5, P11 e P12), objetivo (P1-P4, P7, P8, P11, P12 e P13), observações (P2, P8, P10 e P14), pesquisa (P2, P3, P4, P5, P7, P8, P10, P13 e P14), população (P4, P5, P7, P10, P11, P12 e P14), porcentagem (P4, P5, P7 e P13), problema (P1, P7, P11, P12 e P14), projeto (P1-P5, P8, P11, P12 e P14), questão (P2, P4, P10 e P13), questionário (P4, P5, P7, P8, P10 e P14), resultado (P1-P6, P8-P14), técnica (P1, P2 e P12), tecnologia (P3, P5 e P11), tema (P1-P4, P6, P7, P12 e P14) e trabalho (P3, P8, P9, P10, P11 e P13). Os conceitos mais recorrentes podem ser visualizados na FIG.2, representados por 38 nós e 135 relacionamentos:

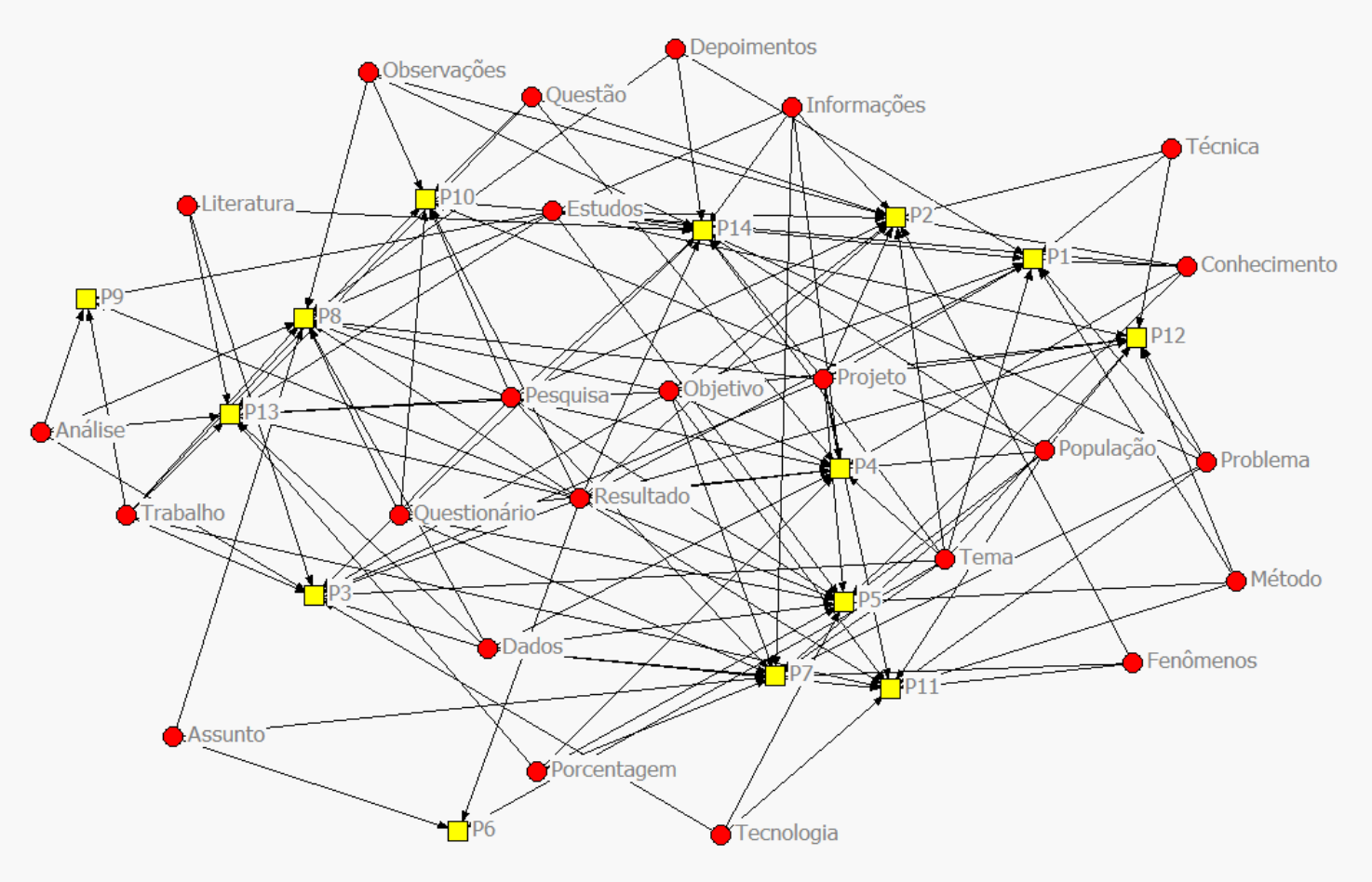

Figura 2: Pesquisadores e conceitos mais recorrentes

Fonte: Dados da pesquisa (2009).

Dentre os recursos disponibilizados pelo software, foi possível identificar a medida de centralidade em relação aos conceitos e aos pesquisadores, por meio do dispositivo Degree, que permitiu contemplar o número de relacionamentos entre os nós da rede. $\mathrm{O}$ conceito com maior medida de centralidade foi o de "resultados", utilizado por 13 pesquisadores. Presente em diferentes zonas de localização do corpus, o significado se manteve permanente em todas as pesquisas; constituindo-se o mais representado de toda a amostra. Seguem-se a ele os 
conceitos de "objetivo", "pesquisa" e "projeto", utilizados com correspondência semântica por nove pesquisadores dentro da rede, respectivamente:

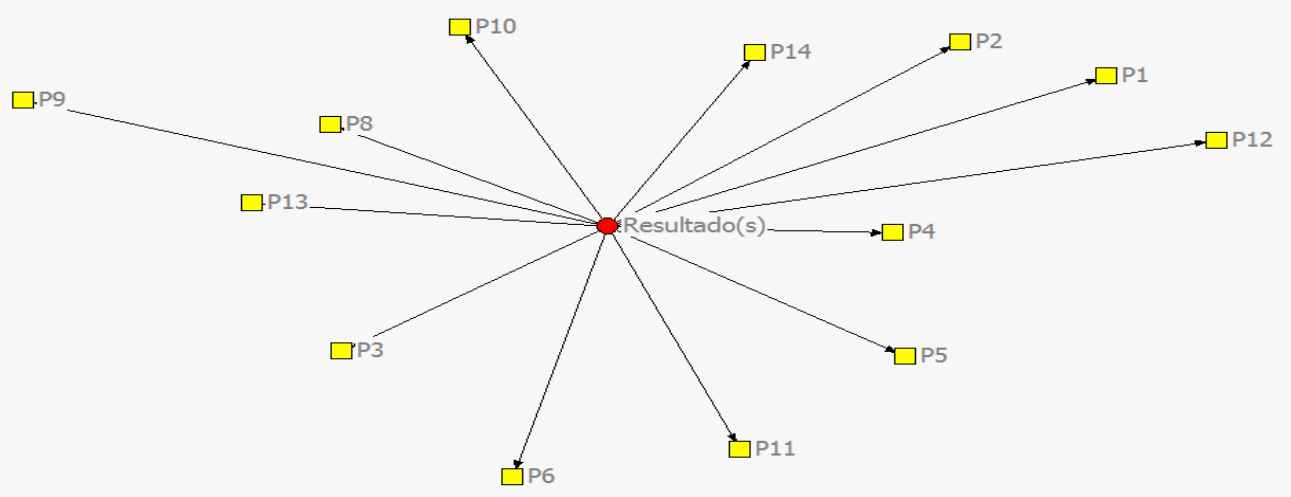

Figura 3: Conceito central

Fonte: Dados da pesquisa (2008).

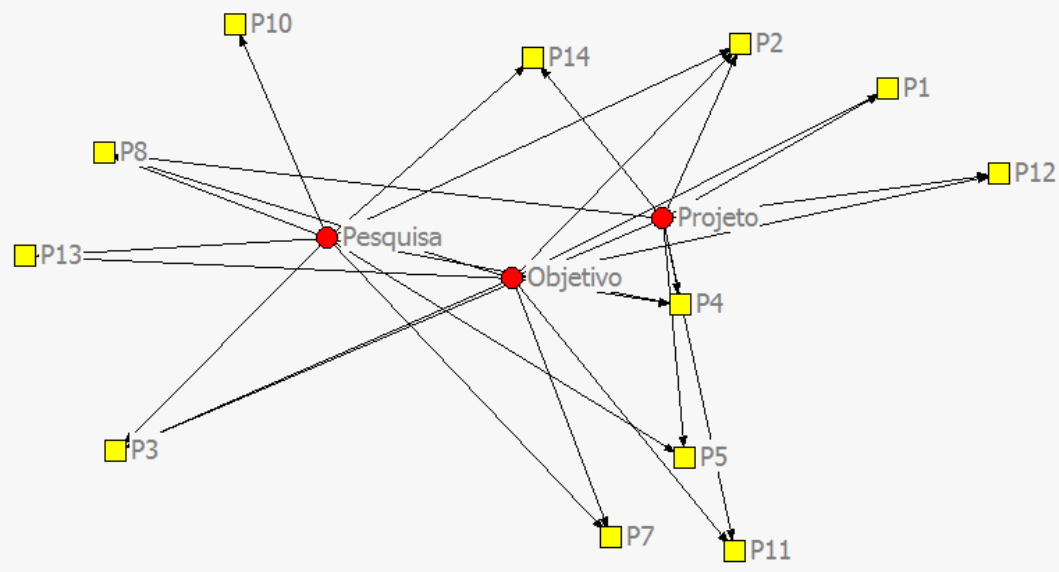

Figura 4: Conceitos principais

Fonte: Dados da pesquisa (2009). 
No corpus, foi possível verificar relações de equivalência, como a sinonímia ${ }^{4}$, por meio dos conceitos estudo/trabalho/pesquisa e pesquisa/monografia, os quais foram preservados em seus contextos originais. Observou-se também que o uso do mesmo conceito por vários pesquisadores manteve um sentido permanente, ou seja, o conceito usado por um pesquisador foi usado por todos os outros com o mesmo significado. A correspondência semântica entre os conceitos representados, mesmo entre os de menor incidência, fez com que a rede se apresentasse como uma estrutura consistente, com certo padrão de regularidade, considerando-se as especificidades das áreas do conhecimento e os períodos e contextos diferenciados de produção das pesquisas.

Outra análise possível foi o relacionamento conceitual entre as temáticas de pesquisa propostas pelo CNPq nas edições do Prêmio Jovem Cientista, como alimentos (2004), educação (2001/2008), energia elétrica (2002), meio ambiente (2003/2006) e saúde (1999/2005), conforme observado na FIG. 5 a seguir:

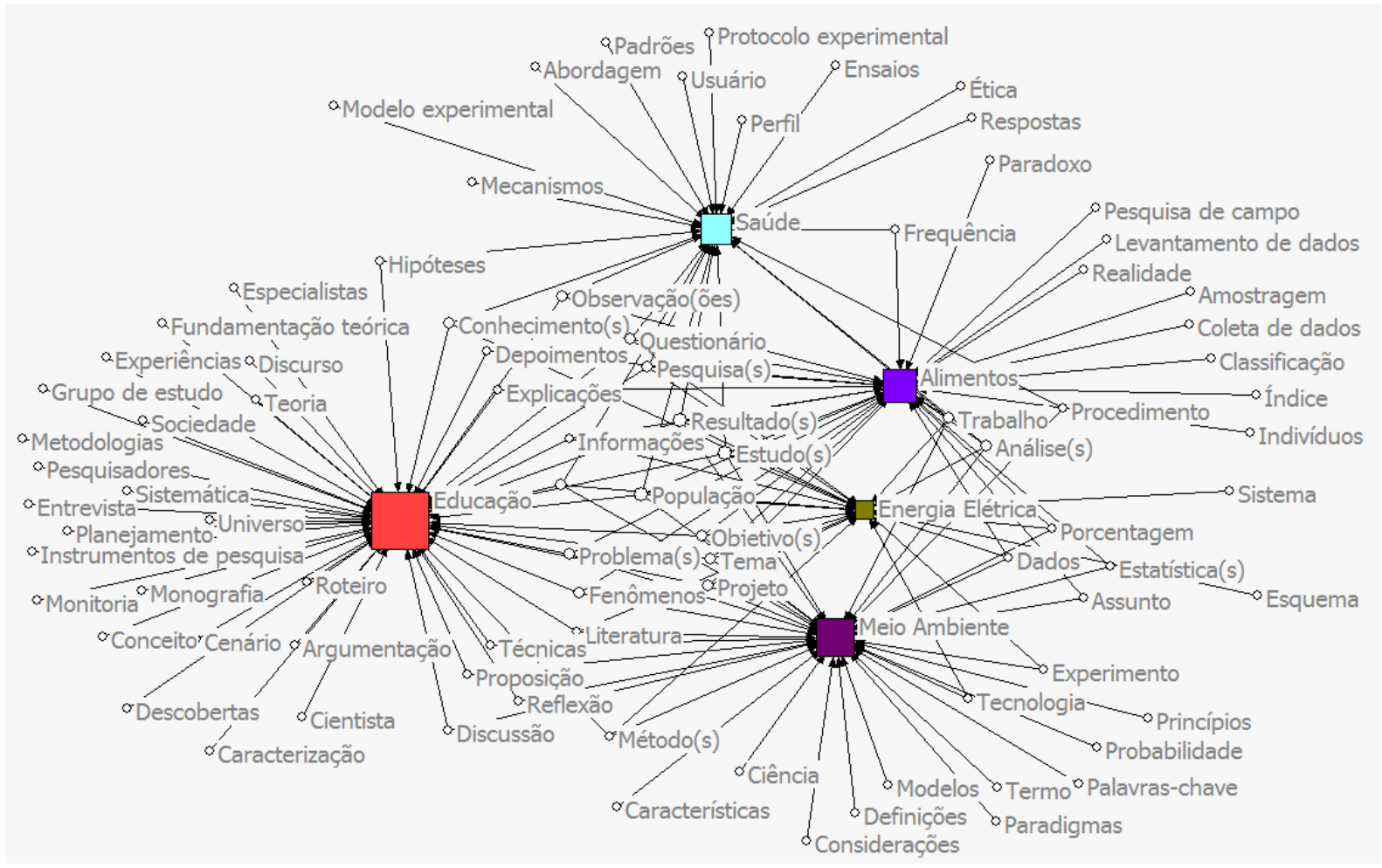

Figura 5: Conceitos e temáticas de pesquisa

Fonte: Dados da pesquisa (2009).

4 No campo da linguagem, diz-se sinonímia quando se usa grafias diferentes para representar o mesmo significado. 
O que se pôde constatar foi o relacionamento conceitual das temáticas, em que todas elas, em maior ou menor grau, relacionam-se entre si na seguinte proporção: educação - 46 relacionamentos, meio ambiente - 34 relacionamentos, alimentos - 30 relacionamentos, saúde - 23 relacionamentos e energia elétrica - 21 relacionamentos.

Ficou evidente a presença de diálogos interdisciplinares no interior dos trabalhos, principalmente envolvendo questões entre educação e eletricidade; energia elétrica e economia; energia elétrica, questões sociais e economia; nutrição, problemas sociais, informação, economia e geografia; nutrição e questões sociais; saúde e estética; meio ambiente, tecnologia e física; educação e sociedade. Todas as pesquisas têm caráter de pesquisa aplicada, reflexo da proposta do prêmio de propor soluções para problemas cotidianos que afligem a sociedade brasileira.

\subsection{Análise comparativa com a estrutura do artigo científico}

Utilizou-se também como método de abordagem a analogia do corpus com a estrutura do artigo científico, segundo os parâmetros estabelecidos pela Associação Brasileira de Normas Técnicas (ABNT), por meio da norma NBR 6022. A análise comparativa foi feita com os objetivos de complementar os resultados alcançados na análise de conteúdo e proporcionar mais conhecimento sobre as pesquisas dos estudantes, já que se percebeu que uma das fragilidades da proposta do concurso é a disponibilização restrita do material produzido pelos jovens pesquisadores.

O corpus foi analisado segundo a presença dos elementos pré-textuais, textuais e pós-textuais, que caracterizam o plano de exposição do artigo científico. Dentro da perspectiva de que "todo texto possui uma lógica" (CORACINI, 2003, p. 325), observou-se o predomínio da lógica do discurso científico. A análise comparativa reforçou a tese de que os trabalhos incorporam elementos de tal discurso. Dentre eles, a lógica e apresentação do raciocínio e do desenvolvimento das ideias em introdução, desenvolvimento e conclusão. Embora não se possa afirmar que essa foi, a priori, uma iniciativa dos jovens pesquisadores, já que é uma exigência do concurso. $\mathrm{O}$ fato é que praticamente todos os trabalhos se submeteram a tal plano de exposição. 
Com relação aos elementos pré-textuais, todos os trabalhos apresentavam título, autor, tema, data de publicação, local (cidade), nome da escola e do orientador. No entanto, a ausência de palavras-chave e de um pequeno currículo dos autores comprometeu um pouco a qualidade da apresentação. Lendo os trabalhos, não foi possível, por exemplo, obter informações sobre a formação e atuação profissional do orientador; quando muito foi apresentado o seu e-mail de contato. Resumos também não foram identificados nos trabalhos, os quais poderiam auxiliar na seleção das leituras.

$\mathrm{Na}$ introdução dos trabalhos, o que mais se observou foi a preocupação dos estudantes em fazer uma contextualização do tema, em apresentar o objeto de estudo, os objetivos, a justificativa, o problema de pesquisa e as motivações pessoais. A explicitação do método foi encontrada em alguns trabalhos de forma mais restrita. Apenas um trabalho sugeriu hipóteses para a construção da pesquisa na introdução. No geral, o que se observou foi a ausência de pressupostos teóricos ou de hipóteses nas pesquisas.

No desenvolvimento do trabalho, a norma recomenda que sejam apresentados a fundamentação teórica, a metodologia, os resultados e a discussão do problema. Foram observados, com frequência, no corpo dos trabalhos, elementos infográficos (figuras, mapas, tabelas, quadros) e a explicitação da metodologia. Com relação à fundamentação teórica, alguns autores elaboraram citações com o cuidado de observar os critérios da ABNT, porém outros não se preocuparam com esse quesito da pesquisa. O mesmo ocorreu com o esclarecimento sobre a data de realização da pesquisa. Notas de rodapé foram elementos ausentes em todos os trabalhos examinados.

Na conclusão dos trabalhos, a maioria dos autores apresentou ou retomou os dados da análise, fez a discussão dos mesmos e recomendações para trabalhos futuros. A maioria dos trabalhos apresentou as referências segundo as normas da $\mathrm{ABNT}$, enquanto alguns pesquisadores não explicitaram as fontes consultadas. Algumas pesquisas se utilizaram de fontes exclusivamente em língua inglesa. Observa-se também que os pesquisadores fizeram uso intenso dos anexos em seus trabalhos. Como parte dos elementos pós-textuais, percebeu-se a ausência de qualquer indicador do trabalho em língua estrangeira, seja título, palavras-chave ou resumo. Devido à dinâmica e abrangência do prêmio, seria importante também que fossem disponibilizados tais indicadores em língua inglesa. 
Enquanto o concurso propõe a elaboração de redação, a maioria das pesquisas dos estudantes incorporou elementos do artigo científico, embora não fosse essa, a priori, uma exigência do prêmio. O perfil discursivo dos pesquisadores indicou uma preocupação, em boa medida, com o rigor científico, com a explicitação do problema de pesquisa, dos objetivos, da metodologia e das conclusões da pesquisa. O uso de um vocabulário comum e bastante recorrente ocorreu, muitas vezes, em função da objetividade, da neutralidade científica, convivendo também com a apresentação subjetiva dos verbos na primeira pessoa do singular e do plural. O que se pôde observar foi uma preocupação com o rigor do método científico, obviamente em consonância com uma proposta de pesquisa para estudantes do ensino médio. Os trabalhos demonstraram uma ordenação lógica das ideias, uma sequência racional coerente com aquela que é exigida para os trabalhos científicos.

Ao investigar a dinâmica dos trabalhos, foi possível perceber características de observação da realidade, curiosidade, inquietação, questionamento, racionalidade, sistematização de ideias, experimentação e capacidade de solucionar problemas. Os mesmos dispunham do artefato de construção de problema de pesquisa, definido e delimitado, normalmente em forma de uma pergunta; referencial teórico com contraposição de pontos de vista e evolução da temática; metodologia, pela aplicação de instrumentos de coleta de dados, comumente questionários e entrevistas; análise e interpretação dos dados e indicações para estudos futuros, premissas de abordagem de trabalhos científicos.

\section{CONSIDERAÇÕES FINAIS}

A técnica da análise de conteúdo se mostrou bastante pertinente para a representação do comportamento informacional e da discursividade científica dos jovens pesquisadores. A dinâmica de produção de conhecimento proposta pelo Prêmio Jovem Cientista e o período de convivência com os jovens pesquisadores, em diferentes espaços e momentos, permitiram a constatação de que o prêmio representou um momento marcante em suas vidas; nas esferas do desenvolvimento da carreira profissional e do aprendizado de pesquisa propriamente dito.

No contexto, as pesquisas envolveram a preocupação direta com os problemas cotidianos da sociedade e a proposição de solução para os mesmos por meio da pesquisa aplicada. Os estudantes demonstraram assimilar o discurso da cidadania e o desenvolvimento da 
consciência de participação e responsabilidade social, sobretudo ao ressaltarem a importância da pesquisa como instrumento viabilizador da melhoria da qualidade de vida. Nesse âmbito, a pesquisa foi considerada também como uma forma de despertar a sensibilidade das pessoas para os problemas vivenciados pela sociedade. Esse foi um sentimento fortemente evidenciado pelos estudantes, proporcionando para alguns um engajamento social posterior ao prêmio, como participação em palestras e debates nas comunidades.

Em relação ao desenvolvimento das carreiras profissionais, boa parte dos estudantes indicou que o prêmio lhes ajudou a despertar o interesse pela ciência e norteou a carreira profissional, ajudando na escolha da profissão. Mais especificamente, o prêmio despertou em alguns jovens o desejo de prosseguir na carreira de pesquisador. E ainda que não tenha influenciado diretamente a carreira profissional, os estudantes acreditavam que a premiação é um diferencial do currículo no espaço acadêmico, principalmente ao se pleitear vagas em programas de pós-graduação stricto sensu. O problema da divulgação dos textos integrais das pesquisas apareceu como fator crítico, pois foi possível perceber que a divulgação dos cadernos de pesquisa é bastante restrita, disponível apenas na Fundação Roberto Marinho; não sendo um material de fácil acesso pelas pessoas e instituições comuns.

O Prêmio Jovem Cientista representou uma oportunidade singular para os estudantes em relação ao aprendizado de pesquisa, em duas vertentes: ao conferir visibilidade e reconhecimento do talento potencial para a pesquisa, que já era manifesto no ambiente escolar, e ao propiciar, para alguns, o primeiro contato com a experiência científica. É importante observar que algumas pesquisas premiadas se deram pela continuidade de projetos começados na escola e em laboratório de pesquisa, os quais foram aperfeiçoados para a inscrição no prêmio.

Para outros, a primeira experiência significativa com a pesquisa científica determinou a incorporação de elementos novos ao acervo de conhecimento pessoal, como a introdução às normas da Associação Brasileira de Normas Técnicas (ABNT) para elaboração de trabalhos científicos, a consciência da necessidade de fundamentação teórica na argumentação científica, o aumento da criatividade e da criticidade em relação à busca de informação, a introdução à prática da pesquisa de campo, a curiosidade e o gosto pela descoberta de coisas novas e a melhoria do processo de escrita e interpretação da língua portuguesa, favorecida pelo hábito da leitura. 
A interpretação dos dados referentes à análise de conteúdo das pesquisas sugeriu a formação para a discursividade científica dos estudantes da educação básica, principalmente os de ensino médio. Embora se acredite que as habilidades de pesquisa possam ser trabalhadas por todo o ensino fundamental, o aprendizado das habilidades informacionais no ensino médio constitui-se em um momento de referência importante, permitindo que a transição para o Ensino Superior aconteça de forma menos traumática. Os estudantes chegam despreparados para a atividade de pesquisa no universo acadêmico, em relação à forma (normalização e apresentação) e ao conteúdo, exigidos no espaço acadêmico (profundidade de abordagem).

Em relação aos estudantes vencedores do Prêmio Jovem Cientista, o envolvimento do orientador e a postura da escola demonstraram ser elementos decisivos para a performance dos estudantes na execução de suas pesquisas. A participação do orientador mostrou-se fundamental em diversos momentos da realização da pesquisa, como na indicação das fontes de informação, no auxílio à normalização, na discussão dos fatos, no auxílio à ordenação das ideias, na construção dos instrumentos de coleta de dados, no projeto como um todo.

\section{REFERÊNCIAS}

ABREU, Vera Lúcia Furst Gonçalves. Pesquisa escolar. In: CAMPELLO, Bernadete et al. A biblioteca escolar: temas para uma prática pedagógica. Belo Horizonte: Autêntica, 2002. p. 25-28.

ASSOCIAÇÃO BRASILEIRA DE NORMAS TÉCNICAS. Informação e documentação Artigo em publicação periódica científica impressa - Apresentação. 2003. Disponível em: $<\mathrm{http}$ ://tjsc25.tj.sc.gov.br/academia/cejur/arquivos/6022artigoempublicaoperidicacientificaim pressa.pdf $>$. Acesso em: 01 Jul. 2010.

BARDIN, Laurence. Análise de conteúdo. Lisboa: Edições 70, 2002.

BERELSON, Bernard. Content analysis in communication research. Glencoe: The Free Press, 1952.

BORGATTI, S. P. NetDraw: Graph Visualization Software. Harvard: Analytic Technologies, 2002.

CAMPELLO, Bernadete. O movimento da competência informacional: uma perspectiva para o letramento informacional. Ciência da Informação, Brasília, v. 32, n. 3, p. 28-37, set./dez. 2003.

CAMPELLO, Bernadete Santos et al. A Internet na pesquisa escolar: um panorama do uso da Web por alunos do ensino fundamental. In: CONGRESSO BRASILEIRO DE 
BIBLIOTECONOMIA E DOCUMENTAÇÃO, 19., 2000, Porto alegre. Informação para a cidadania: anais. Porto Alegre: Actual Informática, s.d. 1 CD-ROM.

CHAUÍ, Marilena. Cultura e democracia: o discurso competente e outras falas. 5. ed. São Paulo: Cortez, 1990.

CHELTON, M. K.; COOL, C. Youth information-seeking behavior: theories, models, and issues. Lanham: The Scarecrow Press, 2004. 403 p.

CORACINI, Maria José R. Faria. As representações do saber científico na constituição da identidade do sujeito-professor e do discurso de sala de aula. In: CORACINI, Maria José (Org.). Identidade e discurso: (des) construindo subjetividades. Chapecó: Argos, 2003. p. 319-336.

FIALHO, Janaina Ferreira. A cultura informacional e a formação do jovem pesquisador brasileiro. Orientadora: Maria Aparecida Moura. 2009. Tese (Doutorado em Ciência da Informação) - Escola de Ciência da Informação, Universidade Federal de Minas Gerais, Belo Horizonte. Disponível em: < http://www.bibliotecadigital.ufmg.br/dspace/handle/1843/ECID7VYQNZ? mode=full>. Acesso em: 01 abr. 2010.

FOCAULT, Michael. A arqueologia do saber. Rio de Janeiro: Forense Universitária, 1987.

GARVEY, William D. Communication: the essence of science: facilitating information exchange among librarians, scientists, engineers and students. Oxford: Pergamon Press, 1979.

KIENTZ, Albert. Comunicação de massa: análise de conteúdo. Rio de Janeiro: Eldorado, 1973. $182 \mathrm{p}$.

KOBASHI, Nair Yumiko. A elaboração de informações documentárias: em busca de uma metodologia. 1994. 195 f. Tese (Doutorado em Ciências da Comunicação)- Escola de Comunicações e Artes, Universidade de São Paulo, São Paulo. 1994.

KUHLTHAU, Carol C. Seeking meaning: A process approach to library and information services. 2. ed. Norwood: Ablex Publishing Corporation, 2004. 247 p.

MAGALHÃES, Maria Helena de Andrade. Uma leitura... da leitura na escola de primeiro grau. 1992. 196 f. Tese (Doutorado em Educação)- Faculdade de Educação, Universidade de São Paulo, São Paulo.

MARTELETO, Regina Maria. Análise de redes sociais - aplicação nos estudos de transferência da informação. Ciência da Informação, Brasília, v. 30, n. 1, Jan./Abr. 2001.

MESQUITA FILHO, Alberto. Ensaios sobre filosofia da ciência. 2000. Disponível em: $<$ http://www.ecientificocultural.com/ECC2/FilCien/cap03.htm>. Acesso em: 3 jul. 2009.

MINAYO, Maria Cecília de Souza. O desafio do conhecimento: pesquisa qualitativa em saúde. 4. ed. São Paulo: HUCITEC-ABRASCO, 1996. 269 p.

NEVES, Iara Conceição Bitencourt. Pesquisa escolar nas séries iniciais do ensino fundamental em Porto Alegre, RS: bases para um desempenho interativo entre sala de aula e biblioteca escolar. 2000. 177 f. Tese(Doutorado em Ciência da Informação e Documentação)- Escola de Comunicações e Artes, Universidade de São Paulo, São Paulo.

ROCHA, Décio; DEUSDARÁ, Bruno. Análise de conteúdo e análise do discurso: aproximações e afastamentos na re (construção) de uma trajetória. Alea, v. 7, n. 2, p. 305-322, 2005. 
VAN DIJK, T. Ideologia - Una Aproximación Multidisciplinaria. Barcelona: Espanha:Gedisa Editorial, 1999.

\begin{abstract}
This paper presents the main achievements of a study sought to investigate the informational behavior of the young Brazilian researcher in the practice of scientific research. It was used a sample of 14 student winners of the Young Scientist Award (Prêmio Jovem Cientista) in the category of high school students. This award is sponsored by the National Council for Scientific and Technological Development $(\mathrm{CNPq})$. By applying the technique of content analysis, the study was set to build the semantic network representation of scientific discourse, drawn from the vocabulary used by these young researchers in their texts. The Young Scientist Award was established as an important moment in the lives of students: on social recognition, career development and learning of research techniques. It was concluded that the contest lacks strength in making the results available to society, mainly concerning the limited access to the winner texts.
\end{abstract}

Keywords: Informational behavior. Scientific research - secondary school. Young Scientist Award (Prêmio Jovem Cientista) - CNPq. Content analysis.

Originais recebidos em: 07/09/2010

Aceito para publicação em: 12/04/2011 